\title{
Curricularização da Extensão Universitária no Ensino Médico: o Encontro das Gerações para Humanização da Formação
}

\section{PALAVRAS-CHAVE \\ - Extensão Comunitária. \\ - Humanização da Assistência. \\ - Currículo. \\ - Envelhecimento.}

\section{KEY-WORDS}

- Community Outreach

- Humanization of Assistance.

- Curriculum.

- Aging.

Recebido em: 6/6/19

Aceito em: 4/7/19

\section{Curricularisation of University Community Outreach in Medical Education: Meeting of Generations for a Humanized Training}

Sinara Monica Vitalino de Almeida ${ }^{\text {『 }}$ Larissa Marcelle Vaz Barbosa ${ }^{I}$

\section{RESUMO}

Este trabalho relata uma experiência de curricularização da extensão universitária no curso médico que teve como objetivos conduzir ações de extensão com vistas ao bem-estar de idosas de uma Instituição de Longa Permanência (ILP), bem como desenvolver habilidades do médico honesto, íntegro, cuidadoso, altruísta e empático consigo, com os "idosos" e com os pares envolvidos nas ações. O modelo usado para organização das atividades combinou métodos de aprendizagem de habilidades por meio da experiência, reflexão crítica sobre as experiências, ambiente de pequeno grupo para suporte e validação e programa longitudinal coeso para desenvolvimento total. As atividades foram vivenciadas em grupos de 12 integrantes, supervisionados por um professor com visitas semanais à ILP de agosto a dezembro de 2018. O modelo utilizado mostrou-se útil para o desenvolvimento de características humanísticas almejadas nos indivíduos em formação. O envolvimento em todas as etapas do processo e o comprometimento com o bem-estar da população selecionada indicam que a curricularização cumpriu seu papel de proporcionar aos estudantes o desenvolvimento de consciência cidadã em paralelo à formação técnica. A instituição de ensino superior deve oferecer continuamente ações para que os estudantes desenvolvam plenamente seu lado humano e preservem as características observadas no contato com a população idosa.

\begin{abstract}
This work describes the experience of including community outreach activities of a university into the medical course curriculum, with the objectives of developing outreach actions directed at the well-being of the elderly from a Long Stay Institution (ILP). At the same time the work promoted the development of honest, caring, selfless professionals empathetic toward the "elderly" and peers involved in the actions. The model used to organize the activities combined methods of learning skills through experience, critical reflection on experiences, small group environment for support and validation, and a cohesive longitudinal program for total development. The activities were experienced in groups of 12 supervised by a teacher with weekly visits to the ILP from August to December of 2018. The model used proved to be useful for the development of humanistic characteristics. Involvement in all stages of the process and commitment to the well-being of the selected population indicate that the curricularisation fulfilled its role of providing students with the development of citizen awareness and technical training. The institution must continually offer actions for students to fully develop their human side and preserve the characteristics observed in their contact with the elderly population.
\end{abstract}




\section{INTRODUÇÃO}

A formação médica evoluiu rapidamente nas últimas décadas sob a influência do desenvolvimento tecnológico e das mudanças epidemiológicas e sociais do período. Essas mudanças requerem alterações na estrutura curricular das escolas médicas com vistas à formação de um profissional com perfil que atenda às necessidades vigentes. Alguns autores falam da formação do "novo profissional"1, enquanto outros refletem sobre a necessidade de resgatar valores e aspectos perdidos na história da evolução do ensino médico com disciplinas transversais ao longo da formação, como, por exemplo, Bioética, Filosofia, História e Socioantropologia ${ }^{2,3}$.

Esse novo profissional almejado, muitas vezes, é denominado "humanizado", numa contraposição a indivíduos formados que supervalorizam e evidenciam habilidades exclusivamente técnicas em detrimento de características pessoais que permitem um bom relacionamento com o paciente e com as equipes envolvidas no ambiente de trabalho ${ }^{4}$. Independentemente da nomeação atribuída ao profissional que se pretende formar, é necessário refletir sobre quais metodologias podem favorecer o desenvolvimento do profissional com valores humanos. Segundo Cohen e Sherif ${ }^{5}$, os valores incluem honestidade, integridade, cuidado, compaixão, altruísmo, empatia e respeito por si, pelos pacientes, por seus pares e por outros profissionais envolvidos no cuidado. Assim, uma questão importante a que este trabalho busca responder é: que processos podem favorecer o desenvolvimento desses valores no indivíduo em formação?

Historicamente, os currículos das escolas médicas tiveram como foco principal o entendimento dos mecanismos fisiopatológicos e a proposição e utilização de práticas mais efetivas para a cura das doenças que afetam a humanidade, concomitante a uma negligência crescente no que se refere a um dos pontos mais importantes da prática médica: a relação médico-paciente ${ }^{6}$. Na atuação profissional, a relação médico-paciente passou a ser ignorada por causa da rotina de trabalho, na qual o médico atende muitos pacientes em curto tempo e com qualidade insatisfatória. As consultas são rápidas e o contato com o paciente é efêmero e superficial. Esse contexto favorece a formação de um profissional preocupado, principalmente, com a doença do paciente, numa perspectiva fragmentada em detrimento de uma visão integrada. Ou seja, um dos desafios das escolas médicas é romper com esse modelo de formação que desumaniza o indivíduo durante o curso. Vale salientar que um modelo de formação é algo complexo, resultante de inúmeros aspectos históricos. Por isso, as mudanças necessárias no perfil do profissional médico formado exigem esforços multiprofissionais dos docentes, diretores de instituições, gestores de saúde, preceptores e estudantes, com conteúdos e estratégias curriculares que direcionem para o alcance dos objetivos propostos 5 .

Contudo, o cenário nacional brasileiro indica que tanto o curso médico quanto os demais cursos superiores precisam passar por uma reformulação em suas ações e organizações curriculares, a fim de possibilitar que o estudante seja o protagonista de sua formação para o desenvolvimento profissional, bem como uma formação cidadã que permita um autorreconhecimento como agente de garantia de direitos, deveres e de transformação social. Visando a esse duplo desenvolvimento durante os cursos de graduação, o Plano Nacional de Educação (PNE) de 2014-2024 trouxe como uma de suas estratégias (12.7) a integralização de no mínimo $10 \%$ do total de créditos curriculares exigidos durante a graduação por meio de programas e projetos de extensão em áreas de pertinência social7.

Portanto, a curricularização da extensão universitária desafia as instituições de ensino superior brasileiras a repensarem suas concepções e práticas extensionistas, o currículo e o papel da universidade na sociedade ${ }^{8}$. Mais ainda, trata-se de uma oportunidade para reformular os processos de formação da graduação, saindo da esfera dicotomizada teoria-prática com a proposição de processos integrados de natureza interdisciplinar, político-educacional, cultural, científica e tecnológica que permitam uma interação transformadora entre as instituições de ensino superior e os outros setores da sociedade, por meio da produção e da aplicação do conhecimento, em articulação permanente com o ensino e a pesquisa ${ }^{9}$.

Dessa forma, a concepção de extensão utilizada aqui se embasa na interação dialógica entre a universidade e setores sociais por meio de uma relação marcada pelo diálogo e troca de saberes, superando-se, assim, o discurso da hegemonia acadêmica e substituindo-o pela ideia de aliança com movimentos, setores e organizações sociais. Esta é a concepção concebida com base nas reflexões e experiências do Fórum de Pró-Reitores das Instituições Públicas de Educação Superior Brasileiras (Forproex), que tem como diretrizes a interdisciplinaridade e interprofissionalidade, a indissociabilidade entre ensino, pesquisa e extensão, o impacto na formação do estudante e a transformação social ${ }^{10}$.

Para atender as necessidades de formação humanizada e de reconexão social/territorial do ensino superior com a sociedade, a extensão foi curricularizada no curso de Medicina da Universidade de Pernambuco (UPE), campus Garanhuns, com ações de extensão voltadas para uma necessidade social pertinente: o envelhecimento. $\mathrm{O}$ Brasil está envelhecendo ${ }^{11}$. As estatísticas referentes ao número de idosos demonstram a inversão da pirâmide etária e indicam que a formação técnica e 
humana superior precisa atender, com recursos humanos, essa nova realidade demográfica nacional.

Este artigo descreve as bases teóricas e o percurso prático utilizados na curricularização da extensão universitária no curso médico da UPE-Garanhuns, que tiveram os seguintes objetivos: desenvolvimento de ações de extensão com vistas ao bem-estar de idosas de uma Instituição de Longa Permanência (ILP), paralelo ao desenvolvimento de valores no médico humano segundo definição de Cohen e Sherif ${ }^{5}$ - honesto, íntegro, cuidadoso, altruísta e empático consigo, com os "idosos" e com os pares envolvidos nas ações.

\section{MÉTODO}

Este estudo é descritivo, do tipo relato de experiência, com exposição da organização curricular e vivência da extensão no curso médico da UPE-Garanhuns durante um semestre letivo. Como a legislação preconiza a curricularização de $10 \%$ das atividades por meio de atividades na comunidade ${ }^{7,9}$, houve adaptação do projeto pedagógico do curso, com destinação de 60-120 horas semestrais a esta finalidade, do primeiro ao oitavo período, tendo como alvos as seguintes populações: idosos, crianças/escolares, comunidades quilombolas, gestantes, hipertensos, diabéticos, obesos e indivíduos com transtornos mentais. A cada semestre, ações específicas serão desenvolvidas com as populações-alvo, todas elas embasadas nos princípios e modelo organizacional descrito aqui. A primeira população-alvo selecionada foi a idosa de uma ILP cujo objetivo é acolher pessoas idosas em caráter permanente e que atende, exclusivamente, mulheres. Localizada na cidade de Garanhuns, a instituição contava, no período de execução, com cerca de 70 idosas, das quais 30 eram acamadas. As atividades desenvolvidas foram aprovadas pelo Comitê de Ética institucional (CAAE: 68586217.9.0000.5207).

O modelo usado para organização das atividades foi o descrito por Branch ${ }^{12}$, que combina os seguintes métodos: (a) aprendizagem de habilidades por meio da experiência; (b) reflexão crítica sobre as experiências; (c) ambiente em pequeno grupo para suporte e validação; (d) programa longitudinal coeso para desenvolvimento total. Para a vivência das atividades, a turma do primeiro período, composta por 36 estudantes, foi dividida em três grupos de 12 integrantes cada e contou com a orientação de um professor. Semanalmente, um grupo visitava a ILP, enquanto os demais planejavam ou refletiam sobre visitas realizadas. As atividades foram vivenciadas de agosto a dezembro de 2018. A Figura 1 apresenta o esquema de organização das atividades.

Cada visita tinha objetivo previamente definido, com a proposição de atividades específicas. Os objetivos das quatro

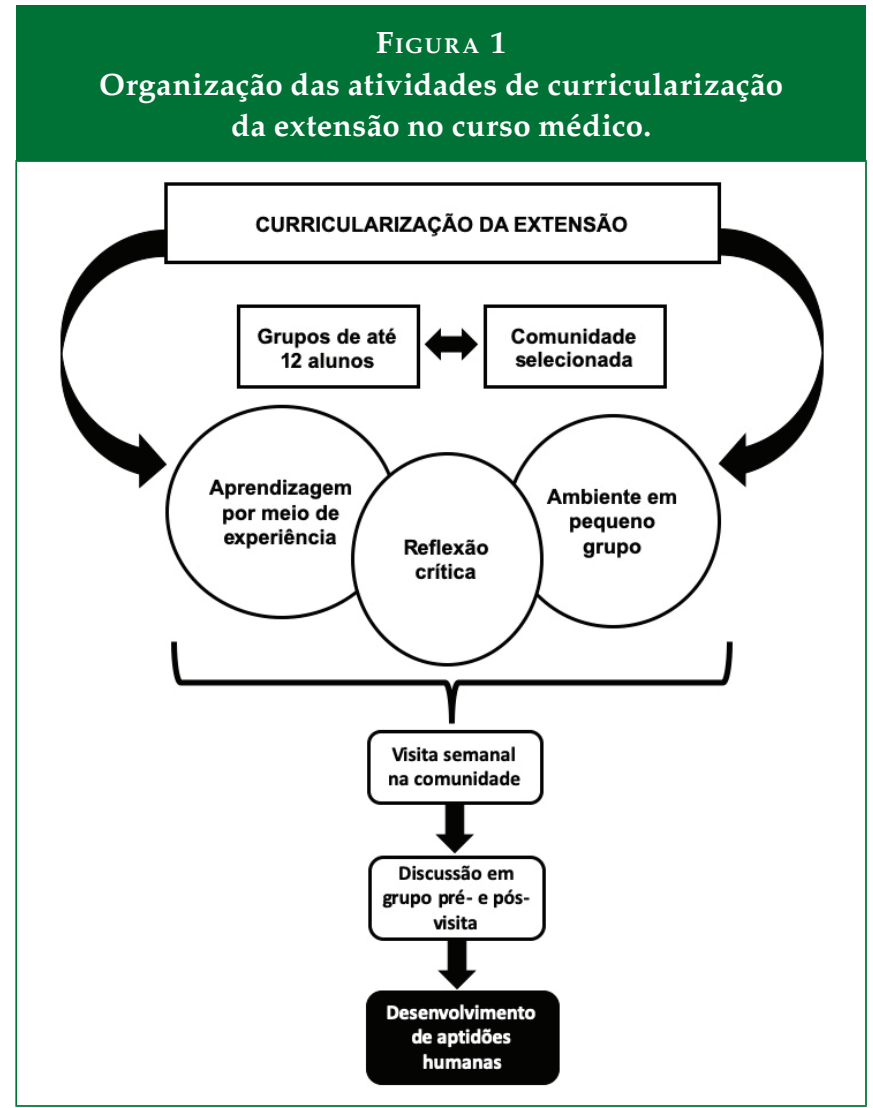

Fonte: Projeto Pedagógico do Curso de Medicina da UPE-Garanhuns.

visitas foram: (a) conhecer e treinar a escuta qualificada por meio da coleta de história de vida das idosas da ILP; (b) utilizar a música e a dança para movimentação corporal e como elo entre as gerações; (c) trabalhar contação de história das vivências prévias na ILP para recordação recente das memórias construídas $^{13}$; (d) reconhecer e tentar atender as necessidades afetivas do idoso. Após cada visita, os estudantes confeccionavam uma narrativa sobre as experiências vividas para compartilhamento e reflexão em grupo. Esses momentos foram mediados pelo professor por meio da facilitação ${ }^{14}$.

Para explicitar as emoções e sentimentos dos estudantes e proporcionar o diálogo entre as experiências vividas e os valores do profissional almejado, foi utilizada a atividade denominada "viagem educacional", conforme Mourthé Jr. et al. ${ }^{15}$, por meio de filmes e visitas. Foram selecionados quatro filmes que abordam algum aspecto do envelhecimento: Minhas tardes com Margueritte; O estagiário; Sabor da vida; e Para sempre Alice. No primeiro momento, em grande grupo, os participantes foram expostos ao filme com vistas à mobilização de emoções. No segundo momento, em pequenos grupos, os indivíduos compartilhavam, mediante facilitação, as emoções e sen- 
timentos mobilizados durante a atividade, ou seja, pretendia-se a explicitação das experiências invisíveis, de caráter mental, relacionadas à percepção ou interpretação das emoções. Nesse momento, o professor pedia que cada estudante registrasse numa folha de papel colorida uma ou poucas palavras que expressassem suas emoções e/ou a atribuição de significados promovidos pelo filme ou atividade com os idosos. Após esse registro, os participantes verbalizavam as associações ou interpretações representadas pelas palavras registradas ${ }^{15}$.

O acompanhamento do processo singular vivido por cada estudante foi feito por meio do compartilhamento de portfólios construídos individualmente e que serviu de instrumento para avaliar o desenvolvimento dos valores humanos esperados, segundo Villas-Boas ${ }^{16}$, e como fonte de dados, como descrito por Valente e Rezende ${ }^{17}$. A coleta de dados nos portfólios foi realizada da seguinte forma ${ }^{18}$ : os portfólios foram requeridos aos estudantes no início do semestre com o objetivo de registro, reflexão e explicitação das conquistas ao longo do processo. As últimas versões dos portfólios, compartilhadas no final do semestre, foram lidas e analisadas como dispositivos comunicativos metodologicamente desenvolvidos na construção de versões sobre os eventos vivenciados, considerando os contextos, os objetivos propostos, as atividades e respectivas intencionalidades educacionais. A análise qualitativa foi feita pela síntese da análise de conteúdo descrita por Mayring ${ }^{19}$.

\section{RESULTADOS E DISCUSSÃO}

O desenvolvimento de habilidades e atitudes requer experiência prática, e com a chamada formação humanizada não é diferente ${ }^{12}$. O alcance deste objetivo requer a vivência de atividades, além da discussão teórica de componentes relativos ao que se espera desse profissional. Não é recente o uso de estratégias no ensino médico para desenvolver atitudes humanas nos indivíduos que incluem acompanhamento de um supervisor durante as aulas práticas dos estudantes, com reflexão durante e após as entrevistas com pacientes reais ou padronizados e simulação com feedbacks dos pares e facilitador ${ }^{20-22}$. Essas estratégias têm demonstrado resultados satisfatórios, mas a inserção do estudante na comunidade permite a exposição à complexidade social e o desenvolvimento de habilidades e atitudes para trabalhar com o contexto do momento. Ou seja, o indivíduo desenvolve a aptidão da inteligência com vistas à recuperação das informações para situá-las num contexto e num conjunto ${ }^{23}$.

A sociedade necessita do olhar atento da universidade. Existem populações mais vulneráveis e que urgem uma atenção especial mediante a formação de recursos humanos para atender aos aspectos do cuidado. Para a vivência das ativida- des da curricularização da extensão deste trabalho, foi selecionada uma população-alvo de uma ILP composta por indivíduos que foram majoritariamente abandonados e que não têm suporte familiar por meio de visitas, tampouco suporte afetivo. Uma das finalidades principais da via estudante-idoso era proporcionar tardes de contato para conversa ou qualquer outra atividade que proporcionasse bem-estar. Vale ressaltar que as atividades propostas não só permitiram beneficiar a população-alvo, como possibilitaram à sociedade sentir a universidade e todo o seu potencial, que deve estar a serviço da melhoria dos espaços extramuros. Ou seja, o conhecimento deve ser posto em favor da melhoria da sociedade, o que não ocorrerá se os indivíduos em formação ficarem reclusos durante o curso superior, ouvindo apenas. É ingênuo esperar que, após a conclusão do curso, esses profissionais exerçam sua cidadania e compromisso social. Esse exercício deve ser iniciado durante a formação. A curricularização da extensão permite, portanto, esse iniciar e desenvolver de consciência, compromisso e atitudes para mudar a realidade social ${ }^{24}$.

A primeira visita teve por finalidade desenvolver no estudante a habilidade de escuta e compreensão. Ouvir é fácil, mas compreender o outro exige esforço. Esse era o objetivo explícito para os estudantes antes da visita in loco e que não foi algo simples de se alcançar, uma vez que a maioria das narrativas e reflexões nos portfólios relatou a dificuldade em construir um vínculo de confiança no primeiro contato para que as idosas contassem sua história de vida. Relatos de timidez e medo de ser invasivo foram causas apontadas para as dificuldades enfrentadas. Por meio da reflexão e compartilhamento das narrativas no pequeno grupo, foi possível verificar que os estudantes demonstraram disponibilidade e desejo de saber interagir melhor com o outro - nesse caso específico, com as idosas. O contato inicial desencadeou também uma preocupação com o seu próprio envelhecimento e dos seus familiares, com reconhecimento da importância de projetos sociais para melhoria de aspectos da vida da população idosa, uma vez que a maioria dos estudantes identificou sinais de abandono com saudade do passado familiar. Os estudantes conseguiram descrever a personalidade das idosas e suas limitações físicas ou capacidades preservadas, com muito respeito e admiração por cada história ouvida. Os sentimentos compartilhados com relação ao primeiro contato englobaram alegria por se sentir útil e incapacidade por não conseguir modificar aspectos da vida das idosas, acompanhados de satisfação por estar naquele ambiente e poder aprender com os relatos de vida. Após o compartilhamento em grupo, foi sugerida uma reflexão sobre as conquistas e desafios a enfrentar nos contatos seguintes. $\mathrm{O}$ Quadro 1 compila os principais resultados. 


\section{QUADro 1}

\section{Desafios e conquistas relatados com relação ao primeiro contato entre estudantes e idosos}

Desafios Conquistas

Desenvolver habilidades para melhor comunicação com as idosas, Aquisição de nova visão sobre o envelhecimento e superação das diferenças visando a uma conversa agradável, vencendo a timidez própria ou de idade, com exercício da paciência e compreensão do outro

Ser empático e apresentar interesse pelo outro

Melhoria na capacidade de conversa e interação com os outros e trabalho em equipe para desenvolvimento das atividades

Saber lidar com os aspectos não esperados do contato (choro, raiva, silêncio)

Reconhecimento da importância da estrutura física e opções de atividades de lazer para a população idosa

Ser paciente nos diálogos e ser assertivo nas conversas

Visão do idoso como ser humano dotado de motivação e vontade de viver e de se divertir

Saber iniciar um diálogo com pessoas desconhecidas em situações de vulnerabilidade, reconhecendo as capacidades e limitações próprias e do outro

Compreensão sobre o aspecto inevitável do envelhecimento e sobre a realidade de uma ILP

Saber lidar com os sentimentos que surgem devido à história pessoal própria, como, por exemplo, lembranças de familiares

Desenvolvimento de sensibilidade e aprendizado para lidar com o contato ora prejudicado pelas limitações impostas pelo envelhecimento

Ser sensível e estar aberto à criação de laços afetivos sem ultrapassar os limites do outro

Sentimento de felicidade por ajudar e superação do medo que havia antes do primeiro contato

Propor situações que proporcionem bem-estar às idosas

Superação da timidez e início do desenvolvimento da empatia

Oportunidade de experimentar um curso de Medicina mais humanizado

A palavra empatia foi referida desde a primeira reflexão em grupo tanto como necessidade de desenvolvimento quanto como conquista. Uma das preocupações da curricularização foi proporcionar vivências para que os estudantes aprendam a lidar com as emoções inevitáveis que o contato desencadeia e sejam sensíveis à condição do outro. Segundo Goleman²5, a empatia é a aptidão social de compreensão dos sentimentos dos outros e a adoção da perspectiva deles, com respeito às diferenças no modo como as pessoas encaram as situações vividas. Os relacionamentos são um foco importante, incluindo aprender a ser um bom ouvinte e um bom questionador; distinguir entre o que alguém diz ou faz e nossas reações e julgamentos; ser mais assertivo e aprender a ser cooperativo para a solução de conflitos ${ }^{25}$.

A empatia deve ser incorporada às atividades curriculares para a formação do médico humanizado ${ }^{5}$, uma vez que os estudantes percebem uma perda de seu comprometimento com os valores humanos relacionados à empatia, e essa perda influencia a relação médico-paciente e os resultados do tratamento ${ }^{26,27}$. Por isso, estudantes devem ser expostos a situações que lhes proporcionem ter tempo para ouvir e ser sensíveis a suas emoções e bem-estar ${ }^{5}$. A curricularização da extensão é, portanto, uma oportunidade curricular para os estudantes aprenderem sobre suas emoções e as do outro, do par ou do indivíduo sob cuidado.

A segunda visita teve como foco a vivência de um momento lúdico com música e dança, elementos utilizados recentemente para curricularização da extensão numa comunidade escolar e em oficinas por Ruas et al. ${ }^{28}$ e em projeto de extensão entre idosos e estudantes de Medicina, conforme descrito por Andrade et al. ${ }^{29}$. Nessa segunda visita, os estudantes usaram de criatividade, mostraram disponibilidade para tocar instrumentos e cantar músicas antigas que envolvessem as idosas e não recearam dançar ou ajudar na movimentação, mesmo que limitada, de muitas das senhoras. Os estudantes reportaram o momento como mágico e útil à construção de vínculos e capaz de proporcionar bem-estar à população-alvo, atribuindo ao poder da música o querer cantar de quem já não tem tanta voz e dançar em meio às limitações físicas. A proposição de atividade com música permitiu uma abordagem alegre, pois possibilitou animar o ambiente e quebrou o silêncio que se instalava entre os diálogos da primeira visita.

Além de favorecer o estreitamento do vínculo recém-criado entre estudante e comunidade, a música tem sido pesquisada e utilizada com pessoas idosas com demência. Apesar de os resultados necessitarem de investigações aprofundadas mais controladas, uma revisão de literatura realizada por Baird e Samson ${ }^{30}$ demonstra que o treinamento musical retarda o declínio cognitivo e promove a plasticidade nos cérebros dos idosos com a vantagem de ser amplamente acessível, fácil de utilizar e apreciado pela maioria das pessoas. A música é útil para intervenções, pois ajuda a recobrar memórias e emoções, fornecendo uma conexão com o passado dos indivíduos e sentimentos que interconectam os envolvidos. Neste trabalho, a música serviu como estratégia de comunicação não verbal para estimular as idosas a perceberem os estudantes e 
despertar o desejo de cantar junto, ouvir deles ou dançar com eles. Foi possível unir as diferenças de idade e expressar as emoções e sentimentos além da palavra falada, fortalecendo os laços interativos.

Os vínculos que se formaram a partir das primeiras visitas foram o tema para a terceira visita, em que os estudantes utilizaram fotos de momentos para contar a história construída entre eles. As fotos são experiência capturada, fornecem um testemunho. Elas podem ser mais memoráveis do que vídeos porque são uma nítida fatia do tempo, e não um fluxo. Cada foto é um momento privilegiado, convertido em um objeto diminuto que as pessoas podem guardar e olhar outras vezes. Ou seja, fotografar é atribuir importância e um meio de aprisionar a realidade, entendida como recalcitrante, impossível de fazê-la parar ${ }^{31}$. As fotos foram um substituto da memória para as idosas e um meio para memorar momentos de alegria vividos na ILP. Nesse momento, os estudantes deveriam ser sensíveis para perceber quais idosas tinham a capacidade de recobrar as memórias preservadas e aquelas que não se lembravam dos momentos vividos. Os estudantes ficaram surpresos com a capacidade mantida de algumas e tristes com a inabilidade de outras. Independentemente dos sentimentos despertados, as fotos foram recursos didáticos importantes para trabalhar com os idosos aspectos relativos à memória ${ }^{13}$.

Concomitantes às visitas, as reflexões realizadas no grupo sobre os encontros com a população-alvo e a discussão sobre os materiais estudados foram fundamentais para superar os desafios identificados ao longo do caminho e obter mais conquistas. $\mathrm{O}$ desenvolvimento de valores e de habilidades para lidar com emoções inevitáveis durante o processo vivido foi o objetivo do trabalho em grupo. Entender como as emoções surgem e aprender a lidar com elas correspondem a uma metacapacidade que determina até que ponto podemos usar bem quaisquer outras aptidões que tenhamos, incluindo o intelecto bruto. O desenvolvimento dessa metacapacidade exige autoconsciência para os estados de espírito, ou seja, o indivíduo deve buscar estar consciente de seu estado de espírito no momento em que ele ocorre. A clareza com que sentem suas emoções pode reforçar outros traços de suas personalidades ${ }^{25}$.

Os momentos de compartilhamento em pequeno grupo foram ancorados nos métodos ativos de aprendizagem por meio da facilitação, em que o professor considera a si mesmo como um recurso flexível a ser utilizado pelo grupo, ajudando a trazer à tona e a elucidar tanto os propósitos individuais quanto os mais gerais do grupo. Essa facilitação conta com o desejo do aluno de realizar os propósitos que têm sentido para cada um como força de motivação subjacente à aprendizagem significativa. Ao professor-facilitador cabe organizar os recursos necessários à aprendizagem de modo amplo e estabelecer um clima de receptividade para o compartilhamento dos sentimentos profundos das experiências vividas ${ }^{14}$. Para registrar e acompanhar a trajetória das experiências vividas, na comunidade ou em pequeno grupo, foi escolhido o portfólio. Segundo Valente e Rezende ${ }^{17}$ (p. 151), o portfólio “tem o potencial de contemplar as produções dos alunos em um largo período de tempo [...] e de traduzir não somente sua maneira de pensar (dimensão cognitiva) como seus sentimentos e atitudes (dimensão afetiva) e sua maneira de agir (dimensão procedimental)", visto que sua construção se pauta na reflexão, criatividade, parceria professor-estudante, autoavaliação e autonomia ${ }^{16}$.

As reflexões em grupo visavam expandir as aptidões dos estudantes nos seguintes domínios: (a) conhecer as próprias emoções - ser autoconsciente dos sentimentos que brotam em variadas situações; (b) lidar com as emoções - após identificar a emoção, saber livrar-se daquelas que atrapalham seu rendimento (ansiedade, tristeza, irritabilidade); (c) motivar-se - saber canalizar as emoções para alcançar os objetivos que deseja atingir; (d) reconhecer emoções nos outros - ter empatia, saber escutar as emoções dos que estão ao nosso redor; (e) lidar com relacionamento - a partir do desenvolvimento ou treinamento das habilidades anteriores, o indivíduo saberá a arte de se relacionar ${ }^{25}$. Após cada visita e viagem educacional por meio dos filmes assistidos, os estudantes compartilhavam os sentimentos relacionados às experiências. As palavras utilizadas para expressar os sentimentos foram diversas, incluindo esperança, motivação, gratidão, aprendizagem, ternura, superação, amor, amizade, admiração, se sentir valorizado, compreensão, tristeza, impotência, medo/receio, aceitação, empatia, alegria, raiva, compaixão, afeto, tristeza, felicidade, inspiração, resiliência, surpresa, perseverança, culpa, angústia.

O contato com indivíduo que necessita de cuidado desperta diferentes sentimentos. Uma pesquisa recente realizada por Kaluf et al. ${ }^{32}$, com 120 estudantes de Medicina, sobre os sentimentos em situações práticas no primeiro, terceiro e quinto ano, demonstrou que os sentimentos relatados no primeiro ano são similares aos observados para ações de extensão como a vivenciada neste trabalho e incluem, em ordem de frequência, motivação, satisfação, alegria, realização, empatia, desânimo, esperança, despreparo, aborrecimento, impotência, desilusão, benevolência, tristeza, raiva e perplexidade. É necessário, portanto, criar espaços de reflexão sobre os sentimentos inevitáveis que os estudantes têm quando estão em atividades práticas e oferecer estratégias para suporte e maturação emocional concomitantes ao desenvolvimento técnico. Aqui, a dimensão afetiva foi valorizada, explicitada e refletida por 
meio de compartilhamento em pequenos grupos mediante a facilitação do professor com o intuito de favorecer o desenvolvimento profissional por meio da integração entre emoções e racionalidades, conforme destacado por Mourthé Jr. et al. ${ }^{15}$ (p. 286):

A capacidade de distinguir as emoções no processo conversacional pode tanto contribuir para a compreensão da cultura que ali emerge quanto ajuda os participantes desta atividade a encontrarem, em seus diálogos, refinamentos de linguagem que os permitam compreender os aspectos emocionais que se conservam de forma recorrente na cultura do grupo. Compreender emoções e racionalidades que compõem a cultura em que estamos imersos, assim como os dominios que sustentam nossas atividades no trabalho, pode descortinar novas práticas, considerando-se o que a sociedade espera de um profissional competente.

Essa integração se baseia na premissa da indissociabilidade entre razão e emoção, que permite uma "aprendizagem autoiniciada que envolve toda a pessoa do aprendiz - seus sentimentos tanto quanto sua inteligência - é a mais durável e impregnante" (Roger ${ }^{14}$, p. 164). Segundo Rogers ${ }^{14}$, não se trata de uma aprendizagem "só do pescoço para cima", mas profunda. Por isso, desde a proposição inicial das atividades de curricularização até o último encontro, a reflexão teve papel fundamental para proporcionar aos estudantes avaliarem seu próprio desempenho, contato com as idosas e trabalho em grupo. A capacidade de reflexão foi crescente ao longo do semestre, paralela à abertura para vivenciar as atividades propostas. Essa disponibilidade é fundamental para que a aprendizagem ocorra, como destacado por Bondia-Larrosa ${ }^{33}$ (p. 24):

A experiência, a possibilidade de que algo nos aconteça ou nos toque, requer um gesto de interrupção, um gesto que é quase impossível nos tempos que correm: requer parar para pensar, parar para olhar, parar para escutar, pensar mais devagar, olhar mais devagar, e escutar mais devagar; parar para sentir, sentir mais devagar, demorar-se nos detalhes, suspender a opinião, suspender o juízo, suspender a vontade, suspender o automatismo da ação, cultivar a atenção e a delicadeza, abrir os olhos e os ouvidos, falar sobre o que nos acontece, aprender a lentidão, escutar aos outros, cultivar a arte do encontro, calar muito, ter paciência e dar-se tempo e espaço.

A metodologia utilizada neste trabalho visou proporcionar esse experimentar com o intuito do desenvolvimento e amadurecimento dos estudantes, concomitante à reconexão da universidade com a sociedade por meio da extensão. Espera-se que os futuros profissionais formados sejam tecnicamente competentes, com formação cidadã e valores humanos almejados por todos os envolvidos no ensino médico. Salienta-se que o caráter longitudinal e experiência com outras populações-alvo são passos seguintes para alcançar a formação dos valores referenciados para o profissional humano.

\section{CONSIDERAÇÕES FINAIS}

Neste trabalho foi relatada a experiência da curricularização da extensão no primeiro período do curso médico. A estratégia utilizada foi o modelo combinado de atividades numa ILP com população idosa, vivenciadas em grupos e com a criação de um espaço de reflexão em pequeno grupo com supervisão de um professor. O modelo utilizado mostra-se potente para o desenvolvimento dos valores humanos almejados nos indivíduos em formação, graças ao uso de metodologias ativas pautadas na reflexão acerca das experiências vividas e da prática da facilitação das atividades em pequenos grupos com valorização da dimensão afetiva, com a premissa da indissociabilidade entre razão e emoção. Contudo, é necessário um acompanhamento longitudinal dos estudantes após o primeiro semestre e em outras turmas para consolidação do modelo proposto.

O envolvimento em todas as etapas do processo e o comprometimento com o bem-estar da população selecionada indicam que a curricularização cumpriu seu papel de proporcionar aos estudantes o desenvolvimento de consciência cidadã em paralelo à formação técnica. A população-alvo se beneficiou com a presença, disponibilidade, afeto e cuidado possível para estudantes do primeiro período. O compromisso institucional será oferecer continuamente ações como a relatada aqui para que os estudantes desenvolvam os valores humanos estabelecidos como fundamentais ao exercício profissional médico.

\section{AGRADECIMENTOS}

As autoras agradecem à Pró-Reitoria de Extensão e à Pró-Reitoria de Graduação da UPE pelo suporte no processo de entendimento e implementação da curricularização da extensão no ensino superior; aos responsáveis pela ILP onde foram desenvolvidas as atividades de curricularização da extensão, especialmente às idosas, por receberem nossos estudantes sempre com muito carinho; e aos estudantes do primeiro semestre 2018.2 da UPE-Garanhuns, que abraçaram a curricularização da extensão de forma humana e aberta para o desenvolvimento esperado das aptidões do médico que queremos formar. 


\section{REFERÊNCIAS}

1. Gomes PA, Rego S. Transformação da Educação Médica: É Possível Formar um Novo Médico a partir de Mudanças no Método de Ensino-Aprendizagem?.Revista Brasileira de Educação Médica 2011; 35(4): 557 - 566.

2. Rego S, Gomes AP, Siqueira-Batista R. Bioética e Humanização como Temas Transversais na Formação Médica. Revista Brasileira de Educação Médica 2008; 32(4): 482-491.

3. Ayres JRCM, Rios IC, Scraiber LB, Falcão MTC, Mota A. Humanidades como Disciplina da Graduação em Medicina. Revista Brasileira de Educação Médica 2013; 37(3): 455-463.

4. Rios IC. Humanização: a Essência da Ação Técnica e Ética nas Práticas de Saúde. Revista Brasileira de Educação Médica 2008; 33(2): 253-261.

5. Cohen LG, Sherif YA, Twelve tips on teaching and learninghumanism in medical education. Medical Teacher 2014; 36: 680-684.

6. Ballester D, Zuccolotto SMC, Gannam SSA, Escobar AMU. A Inclusão da Perspectiva do Paciente na Consulta Médica: um Desafio na Formação do Médico. Revista Brasileira de Educação Médica 2010; 34(4): 596-606.

7. Brasil. Lei 13.005, de 25 de junho de 2014. Aprova o Plano Nacional de Educação - PNE e dá outras providências. Disponível em < http:/ / www.planalto.gov.br/ccivil_03/_ Ato2011-2014/2014/Lei/L13005.htm>. Acesso em 12 janeiro 2019.

8. Imperatore SLB, Pedde V, Imperatore JLR. Curricularizar a extensão ou extensionalizar o currículo? Aportes teóricos e práticas de integração curricular da Extensão ante a estratégia 12.7 do PNE." In: XV COLÓQUIO INTERNACIONAL DE GESTÃO UNIVERSITÁRIA - CIGU, Argentina, 2015, ISBN: 978-85-68618-01-1.

9. Brasil. Resolução CNE/CES 7/2018. Diário Oficial da União, Brasília, 19 de dezembro de 2018, Seção 1, pp. 49 e 50.

10. FORPROEX, 2012. Política Nacional de Extensão Universitária. Porto Alegre: UFRGS.

11. Miranda GMD, Mendes ACG, Silva ALA. O envelhecimento populacional brasileiro: desafios e consequências sociais atuais e futuras. Revista Brasileira de Geriatria e Gerontologia 2016; 19(3): 507-519.

12. Branch WT, Teaching professional and humanistic values: Suggestion for a practical and theoretical model. Patient Education and Counseling 2015; 98: 162-167.

13. Sohlberg MM, Mateer CA. Reabilitação Cognitiva: Uma abordagem neuropsicológica integrada. São Paulo: Santos, 2015.

14. Rogers CR, Liberdade para aprender. 4 ed. - Belo Horizonte: Interlivros, 1969.
15. Mourthé Junior CA, Lima VV, Padilha RQ, Integrando emoções e racionalidades para o desenvolvimento de competência nas metodologias ativas de aprendizagem. Interface (Botucatu) 2018; 22(65): 577-588.

16. Villas-Boas BMF. O portfólio no curso de Pedagogia: ampliando o diálogo entre professores e aluno. Educ Soc. 2005;26(90):291-306.

17. Valente SMP, Rezende LA, “O uso do portfólio em um projeto de pesquisa." Estudos em Avaliação Educacional 2006; 17(33): 149-165.

18. Flick U, Introdução à pesquisa qualitativa. $3^{\underline{a}}$ ed. - Porto Alegre: Artmed, 2009.

19. Mayring P, Qualitative Content Analysis. 2000. In: Forum Qualitative Sozialforschung / Forum: Qualitative Social Research, 1(2), Art. 20, http:/ /nbn-resolving.de/urn:nbn:de:0114-fqs0002204.

20. Branch Jr WT, Pels RJ, Calkins D, Forrow L, Harper G, Mandell F, et al. A new educational approach for supporting the professional development of third year medical students. J Gen Intern Med 1995;10:691-4.

21. Branch Jr WT, Kern D, Haidet P, Weissmann P, Gracey CF, Mitchell G, et al. Teaching the human dimensions of care in clinical settings. J Amer Med Assoc 2001;286:1067-74.

22. Branch Jr WT. Notes of a small-group teacher. J Gen Intern Med1991;6:573-8.

23. Morin E. Os setes saberes para a educação do futuro. Lisboa: Instituto Piaget. 2002.

24. Gadotti M. “Extensão Universitária: Para quê?." Brasil: Instituto Paulo Freire, 2017.

25. Goleman D. Inteligência emocional: a teoria revolucionária que define o que é ser inteligente. $2^{\underline{a}}$ ed. - Rio de Janeiro: Objetiva, 2012.

26. Neumann M, Edelhauser F, Tauschel D, Fischer M, Wirtz M, Woopen C, et al. Empathy decline and its reasons: A systematic review of studies with medical students and residents. Acad. Med. 2011; 86:996-1009.

27. Ha J, Longnecker N. Doctor-patient communication: A review. Ochsner. J. 2010; 10: 38-43.

28. Ruas JJ, Santos M, Silva EP. Projeto Clube De Música: Uma Proposta De Curricularização Da Extensão Na Educação Do Campo. CAPIM DOURADO, Palmas, 2018; 01(01): 5964.

29. Andrade TP, Mendonça BPCK, Lima DC, Alfenas IC, Bonolo PF. Projeto Conviver: Estímulo à Convivência entre Idosos do Catete, Ouro Preto, MG. Revista Brasileira de Educação Médica 2012; 36: 81-85.

30. Baird A, Samson S. Music and dementia. In: Altenmüller E, Finger S, Boller F. Music, Neurology, and Neuroscien- 
ce: Evolution, the Musical Brain, Medical Conditions, and Therapies. Elsevier: 2015, p. 207-35.

31. Sontag S. Sobre fotografia. Trad.: Rubens Figueiredo. São Paulo: Companhia das Letras, 2004.

32. Kaluf IO, Sousa SGO, Luz S, Cesario RR. Sentimentos do Estudante de Medicina quando em Contato com a Prática. Revista Brasileira de Educação Médica 2019; 43(1): 13-22.

33. Larrosa JB. Notas sobre a experiência e o saber de experiência. Revista Brasileira de Educação 2002; 19; 20-28.

\section{CONTRIBUIÇÃO DOS AUTORES}

As autoras contribuíram em todas as etapas desde o delineamento do estudo, execução das atividades, análise dos resultados e escrita final do trabalho.

\section{CONFLITO DE INTERESSES}

Sem conflito de interesses a declarar.

\section{ENDEREÇO PARA CORRESPONDÊNCIA}

Sinara Mônica Vitalino de Almeida - sinara.monica@upe.br 